\title{
Visual Evoked Potential Abnormalities in Jaundiced Gunn Rats Treated with Sulfadimethoxine
}

\author{
SARAH SILVER, ${ }^{1}$ HAIM SOHMER, AND JAIME KAPITULNIK \\ Departments of Physiology [S.S., H.S.] and Pharmacology [J.K.], Hebrew University-Hadassah Medical \\ School, Jerusalem 91120, Israel
}

\begin{abstract}
The manifestations of bilirubin encephalopathy include disturbances in the visual pathway (visual gaze paralysis and distorted visual perception). In the young jaundiced Gunn rat (ij) model of hyperbilirubinemia, significant differences in visual evoked potential (VEP) patterns have been recorded during devclopment. In the present study, the effects of sulfadimethoxine (SDM) on VEP and electroretinogram (ERG) were examined in 3-wk-old jj rats. This drug displaces bilirubin from its albumin binding sites in the circulation, shifting it into tissues including the brain. Marked latency prolongations (11-20\%) and reduced amplitudes $(20-64 \%)$ were observed in the different wave components of the VI:P. These changes were evident as early as $2 \mathrm{~h}$ after injection of the drug and persisted thereafter for another 4 h. On the other hand, ERG changes (significant prolongation of
\end{abstract}

ABSTRACT
The manifestations of bilirubin encephalopathy include hearing loss and psychomotor lesions such as cerebral palsy (1, 2 ), as well as disturbances in the visual system which include visual perception impairment and gaze paralysis (1-4). The VEP was shown to be abnormal in hyperbilirubinemic newborns, returning to a normal pattern after exchange transfusion (5). In this laboratory, the VEP of the developing jj Gunn rat (used as a model for neonatal jaundice) was found to be a sensitive marker for the effects of hyperbilirubinemia on the visual pathway (6). The VEP of 3-wk-old jj rats showed prolonged latencies in those animals which subsequently died during the 4th wk of life, compared with that of the surviving $\mathrm{jj}$ rats, suggesting a greater degree of bilirubin-induced damage in the visual pathway in the former animals (6). Shapiro (7) reported that SDM induced severe abnormalities in the evoked potentials of the auditory nerve and brainstem. To study further the role of bilirubin in the above described visual pathway lesion(s), the VEP was recorded in 3-wk-old jj rats treated with SDM. This compound is

Received May 16, 1994; accepted January 24, 1995

Correspondence: Prof. J. Kapitulnik, Department of Pharmacology and Experimental Therapeutics, Hcbrew University-Hadassah Medical School, POB 12272. Jerusalen 91120 , Isracl.

' This work is part of a Ph.D. thesis to be submitted by S.S. to the Senate of the Hebrew Lniversity in Jerusalem. wave b) became apparent in these animals only $6 \mathrm{~h}$ after SDM injection. These results suggest that, although some changes in the retina may occur after a massive entry of bilirubin into the nervous system, the primary damage in the visual pathway after bilirubin exposure is probably beyond the retina. (Pediatr Res 38: 258-261, 1995)

\author{
Abbreviations \\ VEP, visual evoked potential \\ ERG, electroretinogram \\ jj, homozygous recessive, jaundiced Gunn rat \\ Jj, heterozygous, nonjaundiced Gunn rat \\ SDM, sulfadimethoxine
}

known to displace bilirubin from its albumin binding sites in the circulation, shifting it into neural and other extravascular compartments (8-10). The ERG was also recorded to obtain information on the site of lesion in the visual pathway.

\section{METHODS}

Animals. jj and $\mathrm{Jj}$ Gunn rats, 20-22 d old, were obtained from our colony at the Hebrew University-Hadassah Medical School. Female Jj rats were mated with $\mathrm{jj}$ males and were kept together with the offspring on a 12-h light, 12-h dark cycle, at constant room temperature $\left(23-25^{\circ} \mathrm{C}\right)$. The rats were fed rat food containing $11 \%$ fat (Weizmann Institute, Rehovot, Israel) and water ad libitum.

SDM administration. SDM sodium salt (Sigma Chemical Co., St. Louis, MO), dissolved in saline $(20 \mathrm{mg} / \mathrm{mL})$, was injected intraperitoneally $(100 \mathrm{mg} / \mathrm{kg}$ ) to $\mathrm{jj}$ and $\mathrm{Jj}$ rats immediately after the initial baseline VEP and ERG recordings. These recordings were repeated 2 and $6 \mathrm{~h}$ after injection.

Blood samples were taken from the tail vein immediately after the first VEP and ERG recordings (before injection). A second blood sample was taken $6 \mathrm{~h}$ after the injection. Plasma bilirubin levels were determined by the method of Michaelsson (11). 
VEP recordings. Rats were anesthetized by light ether inhalation. The VEP was recorded as described in our developmental study (6). Briefly, the VEP was elicited by high intensity flashes delivered by a Grass PS-2 photostimulator (Grass Instruments, Quincy, MA), triggered by the evoked response system Micro-Shev C-ERA 100 (Micro-Shev, Efrat, Israel) at a rate of $0.5 / \mathrm{s}$. The electrical activity was recorded using needle electrodes, placed at an occipital region and chin, and a ground electrode placed at a hind limb. The recording band pass was $0.8-30 \mathrm{~Hz}$, and $n=64$ traces were averaged. Typical VEP recordings are shown in Fig. 1. At least two traces were recorded for each condition, and average latencies and peak to peak amplitudes of waves $\mathrm{P}_{1}, \mathrm{~N}_{1}$, and $\mathrm{P}_{2}$ were determined with the cursor. An independent observer determined these values without knowing the experimental background of the animals. During recording, body temperature was maintained at $36.5-37^{\circ} \mathrm{C}$ with a heating pad and monitored with a telethermometer (Yellow Springs Instruments Co., Yellow Springs, OH).

ERG recordings. The ERG was elicited using the same stimulus, but a silver ball electrode was placed on the cornea with a drop of saline to improve the contact between the cornea and the electrode. The second differential electrode was placed at the chin, to reduce VEP activity, and a ground electrode was placed at a hind limb (stimulus rate $=0.5 / \mathrm{s}$; band pass $=$ $0.8-30 \mathrm{~Hz} ; n=32$ ). At least two traces were recorded for each condition. Typical ERG recordings (showing waves a and b) are presented in Fig. 1. Results are presented as mean \pm SD, and statistical evaluation was performed using repeated measures analysis of variance.

\section{RESULTS}

The VEP was recorded in $12 \mathrm{jj}$ and $14 \mathrm{Jj}$ rats, $20-22 \mathrm{~d}$ old, originating from five litters. Plasma bilirubin levels in the $\mathrm{jj}$ rats before SDM injection were $12.1 \pm 3.7 \mathrm{mg} / \mathrm{dL}$. Six hours after SDM injection, plasma bilirubin levels decreased to $2.6 \pm$ $1.1 \mathrm{mg} / \mathrm{dL}(p<0.0001)$. Injection of SDM caused marked prolongations of VEP wave latencies in jj rats (Fig. $2 A$ ). This effect was evident as early as $2 \mathrm{~h}$ after injection and persisted for at least an additional $4 \mathrm{~h}$ (Fig. 3). Six hours after SDM injection, jaundiced animals exhibited maximal increases of $8.50 \pm 6.23 \mathrm{~ms}$ for wave $\mathrm{P}_{1}$ (baseline, $35.53 \pm 2.37 \mathrm{~ms}$ ), 8.54 $\pm 4.71 \mathrm{~ms}$ for wave $\mathrm{N}_{1}$ (baseline, $43.89 \pm 6.41 \mathrm{~ms}$ ), and 7.19
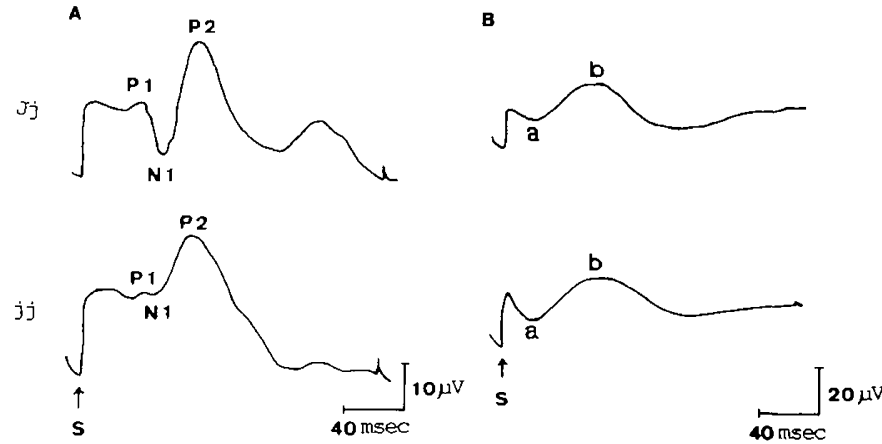

Figure 1. Typical VEP $(A)$ and $\operatorname{ERG}(B)$ recordings in $\mathrm{Jj}$ (above) and $\mathrm{jj}$ (below) Gunn rats. $S$ indicates the time of stimulation.
A
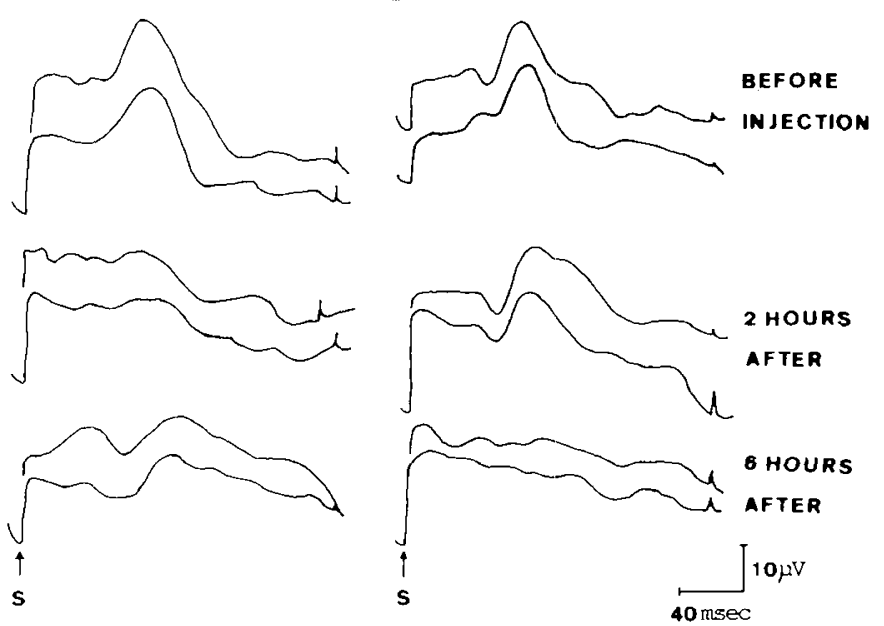

Figure 2. Changes in VEP wave latency and amplitude in two jaundiced (ji) rats after SDM injection. In rat $A$, clear changes in VEP pattern were apparent as early as $2 \mathrm{~h}$ after injection, whereas in rat $B$ there was no clear response 6 $\mathrm{h}$ after injection. $S$ indicates the time of stimulation.

$\pm 5.51 \mathrm{~ms}$ for wave $\mathrm{P}_{2}$ (baseline, $66.62 \pm 3.24 \mathrm{~ms}$ ). On the other hand, the nonjaundiced $\mathrm{Jj}$ rats showed slightly shorter wave latencies at this time.

Amplitudes decreased significantly in jj animals (Fig. 4), whereas there were no statistically significant changes in the $\mathrm{Jj}$ animals. The most remarkable effects of SDM were observed in five $\mathrm{jj}$ rats, in which some or all VEP waves could not be detected after injection of the drug (Fig. $2 B$ ).

The ERG was also recorded in the same rats. Injection of SDM caused a significant prolongation of wave b latency in the jj animals $(p<0.005)$, with no change in wave a latency (Fig. 5). However, this effect on the ERG was first detected only 6 $h$ after injection, whereas the prolongation of VEP wave latencies was already close to maximal as early as $2 \mathrm{~h}$ after administration of the bilirubin-displacing drug. No changes were found in ERG wave amplitudes (data not shown).

\section{DISCUSSION}

SDM induced marked VEP and moderate ERG changes in $\mathrm{jj}$ rats. These changes probably resulted from increased entry of bilirubin into the CNS, because SDM is known to displace bilirubin from its albumin binding sites in plasma, shifting it into extravascular compartments $(8-10)$. It has been shown that, immediately after injection, sulfonamides caused a very rapid decrease in total plasma bilirubin levels and a transient 3 -fold increase in free bilirubin levels, which returned to preinjection values within $30 \mathrm{~min}$ (8). The VEP changes (prolongation of wave latencies and decreased amplitudes) were apparent in jj rats injected with SDM as early as $2 \mathrm{~h}$ after injection, whereas the ERG exhibited a significant prolongation of wave b latency only $6 \mathrm{~h}$ after SDM injection. Thus, the changes in VEP pattern caused by bilirubin are apparently not a direct consequence of damage to the retina, because the retinal changes occurred only after the changes in VEP.

The VEP is thought to be generated in the visual cortex (12-14). Inasmuch as visual cortex damage, e.g. loss of neu- 

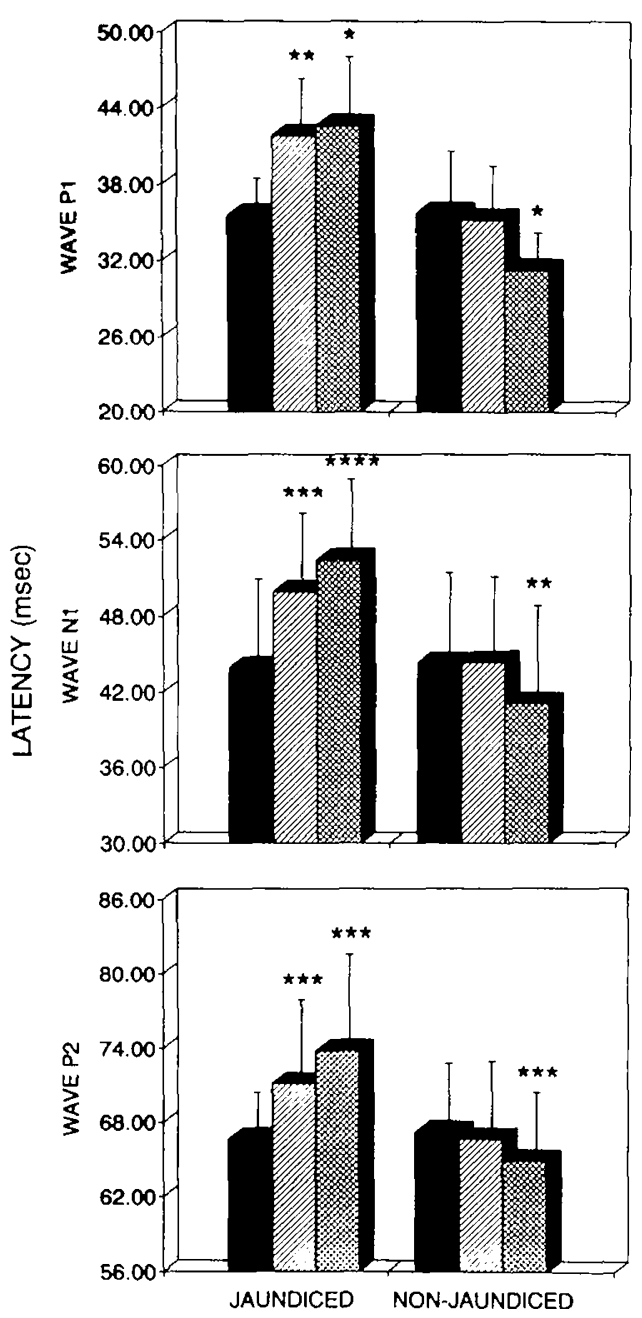

Figure 3. VEP wave latencies before ( $), 2 \mathrm{~h}$ ( administration to $\mathrm{jj}$ and $\mathrm{Jj}$ Gunn rats. Differences compared with baseline (before injection) are statistically significant: ${ }^{*} p<0.05,{ }^{* *} p<0.01,{ }^{* * *} p<$ 0.002 , and ${ }^{* * * *} p<0.0001$.

rons and neuronal degeneration, has been reported in autopsies of children who suffered from hyperbilirubinemia and developed kernicterus (15), the marked changes in VEP caused by $\mathrm{SDM}$ in $\mathrm{jj}$ rats may reflect such damage to the visual cortex, even though histopathologic examinations were not made in this study. We cannot exclude, however, possible damage to the neural pathway between the retina and the visual cortex. In fact, optic nerve degeneration and optic nerve atrophy have been reported in autopsies of children who developed kernicterus $(16,17)$. The effect of SDM on wave b latency of the ERG in jj rats may be a secondary effect on glial cells in the retina, because wave $b$ is thought to be generated by such cells $(18,19)$, and bilirubin has been shown to affect glial cells as well as neurons $(16,20)$.

In a study in hyperbilirubinemic piglets, to which sulfisoxasole was injected, changes were observed in auditory brainstem-evoked responses without affecting serum or cerebrospinal fluid levels of neuron-specific enolase (21). This was interpreted as indicating that overt neuronal damage was not induced over the 6 -h period of the experiment.
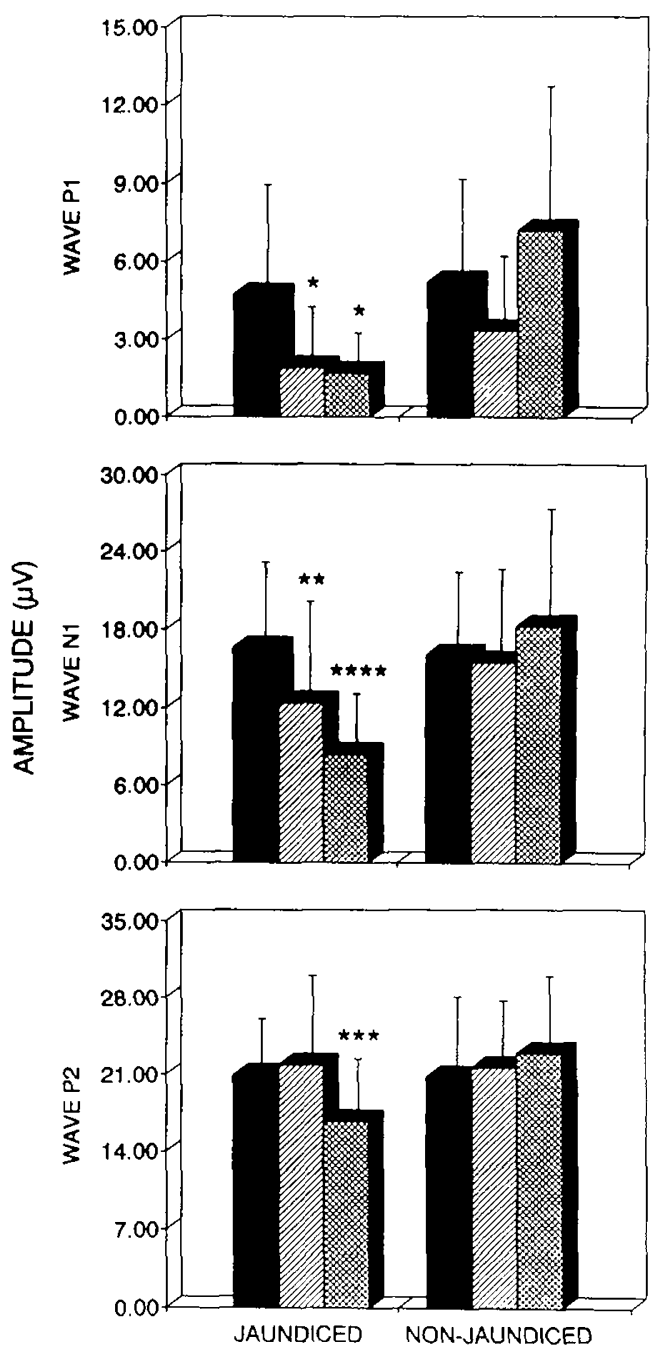

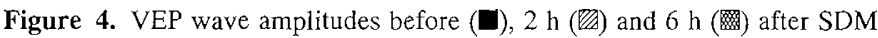
administration to jj and $\mathrm{Jj}$ Gunn rats. Differences compared with baseline (before injection) are statistically significant: ${ }^{*} p<0.05,{ }^{* *} p<0.01,{ }^{* * *} p<$ 0.005 , and $* * * * p<0.0001$.

It should be pointed out that jj rats receiving SDM developed convulsions $8-10 \mathrm{~h}$ after injection, and most of these rats died $10-48 \mathrm{~h}$ after injection. In this respect, it should be borne in mind that VEP changes during early development were more pronounced in the $\mathrm{jj}$ rats who subsequently died during the 4 th wk of life (6).

We have no convincing explanation for the occurrence of slightly shorter VEP latencies after SDM administration to $\mathrm{Jj}$ Gunn rats. However, the latencies of the somatosensory evoked potential waves were also shorter after SDM injection to Jj rats (Silver, S, Sohmer H, Kapitulnik J, manuscript in preparation). Furthermore, VEP latency shortening was also found in Sabra rats treated with SDM in this laboratory (data not shown).

The pronounced changes in VEP of $\mathrm{jj}$ rats after SDM injection, including complete disappearance of waves in some rats, suggest that VEP is a modality with high sensitivity for detection of changes in bilirubin dynamics leading to encephalopathy, and should be incorporated in the evoked potential battery used in the evaluation of bilirubin-induced neurotoxicity in jaundiced newborns. 


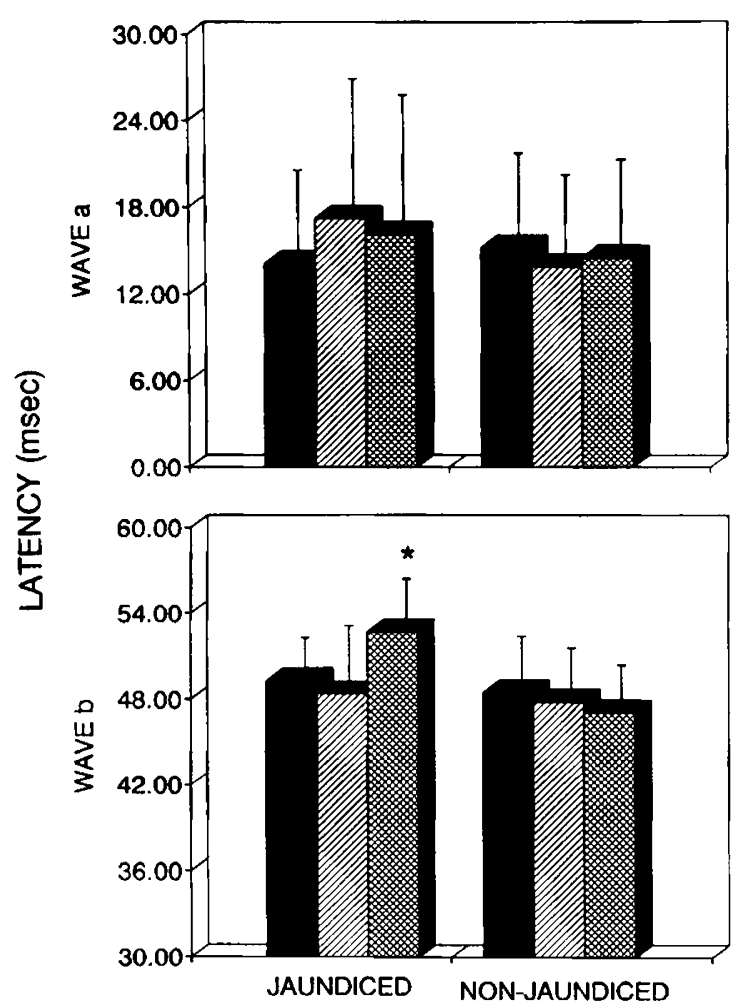

Figure 5. ERG wave latencies before (Ш), $2 \mathrm{~h}$ (ש) , and $6 \mathrm{~h}$ (器) after SDM administration to $\mathrm{jj}$ and $\mathrm{Jj}$ Gunn rats. Only wave b of the ERG exhibited statistically significant changes in latency $\left({ }^{*} p<0.005\right) 6 \mathrm{~h}$ after injection.

\section{REFERENCES}

1. Perlstein MA 1960 The late clinical syndrome of postictcric encephalopathy. Pediatr Clin North Am 7:665-687
2. Hyman CB, Keaster J, Hanson V, Harris I, Sedgwick R, Wursten H, Wright AR 1969 CNS abnormalities after neonatal hemolytic disease and hyperbilirubinemia. Am I Dis Child 117:395-405

3. Naeye RL 1978 Amniotic fluid infections, neonatal hyperbilirubinemia and psychomotor impairment. Pediatrics 62:497-503

4. Hoyt CB, Bilson FA, Alpins N 1978 The supranuclear disturbances of gaze in kernicterus. Ann Ophthalmol 10:1487-1492

5. Chin KC, Taylor MJ, Perlman M 1985 Improvement in auditory and visual evoked potentials in jaundiced preterm infants after exchange transfusion. Arch Dis Child 60:714-717

6. Silver S, Kapitulnik J, Sohmer H 1991 Postnatal devclopment of flash visual evoked potentials in the jaundiced Gunn rat. Pediatr Res 30:469-472

7. Shapiro SM 1988 Acute brainstem auditory evoked potential abnormalities in jaundiced Gunn rats given sulfonamide. Pediatr Res 23:306-310

8. Øie S, Levy G 1979 Effect of sulfisoxazole on pharmacokinetics of free plasma protein-bound bilirubin in experimental unconjugated hyperbilirubinemia. J Pharm Sci 68:6-9

9. Robertson A, Karp W, Brodersen R 1991 Bilirubin displacing effect of drugs used in neonatology. Acta Paediatr Scand 80:1119-1127

10. Schutta HS, Johnson LT 1969 Clinical signs and morphologic abnormalities in Gunn rats treated with sulfadimethoxine. J Pediatr 75:1070-1079

11. Michaelsson M 1961 Bilirubin determination in serum and urine. Studies on diazomethods and a new copper-azopigment method. Scand J Clin Lab Invest 1(suppl):46-47

12. Ducati A, Fava E, Motti EDF 1988 Neuronal generators of the visual evoked potentials: intracerebral recording in awake humans. Electroencephalogr $\mathrm{Clin} \mathrm{Neu}-$ rophysiol 71:89-99

13. Kraut MA, Arezzo JC, Vaughan HG 1985 Intracortical generators of the flash VEP in monkeys. Electroenccphalogr Clin Neurophysiol 62:300-312

14. Kraut MA, Arezzo JC, Vaughan HG 1990 Inhibitory processes in the flash evoked potential of the monkey. Electroencephalogr Clin Neurophysiol 76:440-452

15. Crome $L 1955$ Morphological nervous changes in survivors of severe jaundice of the newborn. J Neurol Neurosurg Psychiatry 18:17-23

16. Burghard E, Schleussing H 1933 Folgezustande des Icterus neonatorum gravis. Klin Wochenschr 12:1526-1529

17. Zimmerman HM, Yannet H 1935 Cerebral sequelae of icterus gravis neonatorum and their relation to kernicterus. Am J Dis Child 49:418-430

18. Stockton RA, Slaughter MM 1989 B wave of the electroretinogram, a reflection of ON bipolar cell activity. J Gen Physiol 93:101-1.22

19. Tomita T, Yanagida T 1981 Origins of the ERG waves. Vision Res 21:1703-1707

20. Amit Y, Brenner T 1993 Age-dependent sensitivity of cultured rat glial cells to bilirubin toxicity. Exp Neurol 121:248-255

21. Hansen TWR, Cashore WJ, Oh W 1992 Changes in piglet auditory brainstem response amplitudes without increases in serum or cerebrospinal fluid neuron-specific enolase. Pediatr Res 32:524-529 